\title{
Pneumopericardium and pneumomediastinum complicating endotracheal intubation
}

\author{
D. O'NeILL \\ M.B., Ch.B., M.R.C.P. \\ D. N. K. SYMON \\ B.Sc., M.B., Ch.B., M.R.C.P. \\ Department of Cardiology, Western Infirmary, Glasgow G11 6NT
}

\begin{abstract}
Summary
Pneumopericardium and pneumomediastinum have been described as complications of endotracheal intubation and assisted ventilation in neonates and children. Here the occurrence of these complications in an adult is described and the possible mechanism discussed.
\end{abstract}

\section{Introduction}

The use of the endotracheal tube during surgery has become the most widely used and acceptable method of providing an airway and of assisting in the ventilation of the patient. Although some complications do arise, the beneficial aspects of the procedure have far outweighed the limitations due to these hazards (Freeman, 1972; McGovern, FitzHugh and Edgemon, 1971). Occasional reports of trauma to the trachea from endotracheal intubation in adults have appeared in the literature (Thompson and Read, 1968) but most have been of children and particularly of newborn infants (Fearon et al., 1966). A combination of surgical emphysema, pneumothorax, pneumomediastinum and pneumoperitoneum has been described (Scott and Viner, 1975) and pneumopericardium has been documented following endotracheal intubation in the neonatal period (Moodie et al., 1976). Mansfield et al. (1973) felt that pneumopericardium occurred almost exclusively in pre-term newborn infants with idiopathic respiratory distress syndrome (IRDS). This complication in an adult is now described.

\section{Case report}

A 27-year-old male with a history of frequent drug overdose was brought to the Accident and Emergency Department of the Western Infirmary, Glasgow, with a history of ingesting 93 tablets of phenobarbitone $30 \mathrm{mg}$ and a quantity of alcohol. On arrival he was drowsy and within minutes became deeply comatose and apnoeic. An endotracheal tube*

\footnotetext{
* 'Clearway' cuffed endotracheal tube, 9 mm (J. G. Franklin and Sons, High Wycombe, Buckinghamshire).

Correspondence: Dr D. N. K. Symon, Department of Child Health, Royal Hospital for Sick Children, Yorkhill, Glasgow G3 8SJ.
}

was promptly inserted by the house physician. This type of tube has a total length of $30 \mathrm{~cm}$ with markings at 22, 24 and $26 \mathrm{~cm}$. It was not trimmed before insertion. Copious secretions were aspirated and intermittent positive pressure ventilation commenced using an Ambu bag. It was then noticed that the left lung was not being inflated and the tube was partially withdrawn. Ventilation with the Ambu bag was continued for 30 minutes until spontaneous ventilation returned. During this period gastric lavage was carried out after an oro-gastric tube had been passed without difficulty.

On admission to the intensive care unit he was noted to have a loud pericardial friction rub audible over the entire praecordium. The heart sounds remained normal. There was no rise in jugular venous pressure and pulsus paradoxus was absent. Chest X-ray showed a pneumomediastinum and pneumopericardium (Fig. 1). The electrocardiogram remained normal throughout his stay in hospital. Blood barbiturate level on admission was 310 $\mathrm{mmol} / \mathrm{l}$.

His subsequent course was uneventful and he recovered full consciousness $15 \mathrm{hr}$ after admission. The endotracheal tube had been in place for $12 \mathrm{hr}$. Follow-up was incomplete as the patient discharged himself from hospital against medical advice $60 \mathrm{hr}$ after admission. However, his friction rub persisted for the duration of his stay in hospital.

Six weeks later he presented himself once again at the Accident and Emergency Department with a fractured left ankle. At that time he had no cardiac signs nor symptoms and the chest X-ray appearances had returned to normal.

\section{Discussion}

Pneumopericardium was first described as a post-mortem finding by Joseph Lieutaud (1767) but it was not until 77 years later that the classic pericardial sound ('Bruit de Moulin') was first described (Bricheteau, 1844). It is a rare but potenially lethal complication of many conditions, and when tension develops within the pericardium the resultant cardiac tamponade necessitates prompt decompression (Khan, 1974). 


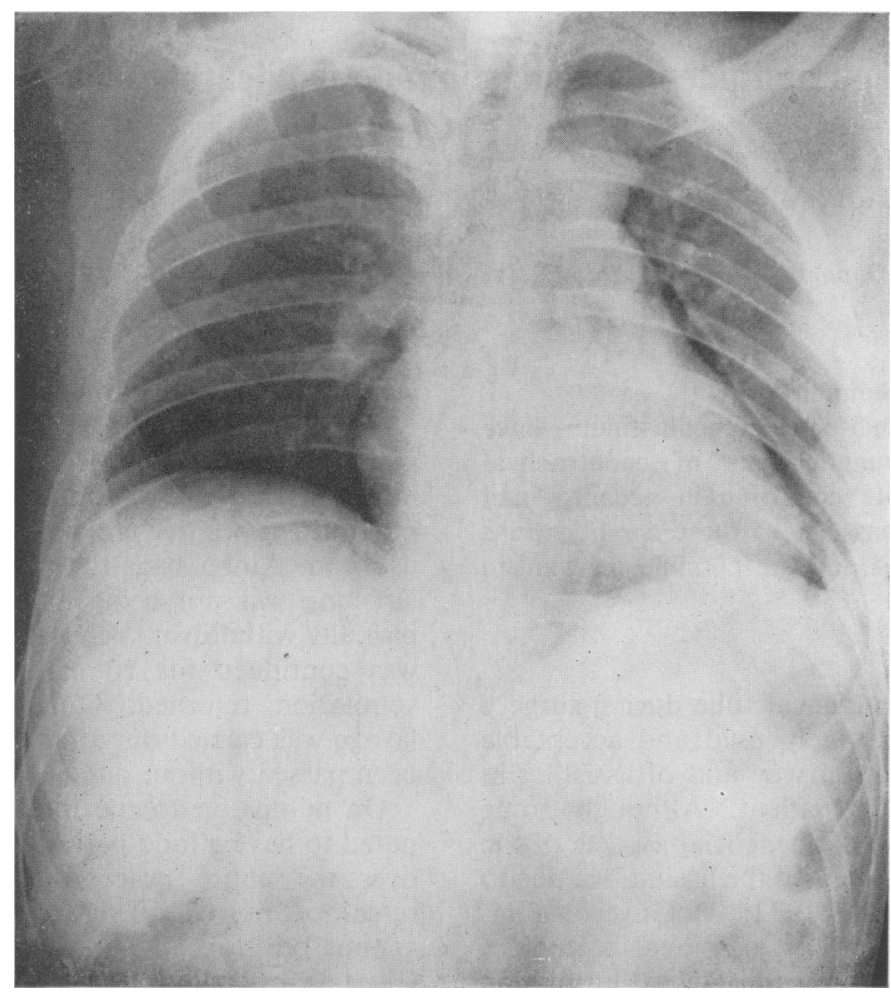

FIG. 1. Chest X-ray on admission to the intensive therapy unit showing pneumomediastinum and pneumopericardium.

Shackelford (1931) while reviewing 76 cases occurring in the previous century noted that more than $66 \%$ had a fatal outcome. Many of these were the result of penetrating injuries or of tuberculosis. Since then, other cases have been described of complicating conditions such as hiatus hernia (Monro et al., 1974), oesophagitis (Curry and Anderson, 1974), lung abscess (Netto, 1944) and even dental extraction (Sandler, Libshitz and Marks, 1975). There is in the literature one instance of pneumopericardium following endotracheal intubation for anaesthesia in a 3.5-month-old boy (Loftis et al., 1962). However, most cases of pneumopericardium occur in newborn infants (Moodie et al., 1976), particularly those treated with continuous positive airways pressure (CPAP) or intermittent positive pressure ventilation with positive end-expiratory pressure (PEEP) for IRDS (Mansfield et al., 1973; Matthieu et al., 1970).

The mechanism causing pneumopericardium is probably related to the rise in intra-bronchial air pressure (Johannides and Tsoulos, 1930), brought about by the CPAP or PEEP.

Histological preparations have demonstrated a site of potential weakness where the parietal pericardium is reflected on to visceral pericardium near the ostia of the pulmonary veins (Mansfield et al., 1973). The pericardial collagenous tissue is not continuous around the point of reflection but tends to pass peripherally, contributing to the perivascular sheath. Air dissecting through the appropriate layer of the perivascular sheaths could enter the pericardial sac with relative ease at the site of reflection, since the only obstacles would be thin layers of mesothelium and areolar tissue. In the present patient it seems likely that the mechanism was through direct damage to the trachea (Thompson and Read, 1968) or right main bronchus, with the air then tracking down to the pericardial sheath.

This case illustrates that endotracheal intubation is a procedure which continues to have a morbidity in adults as well as in children, and insertion of endotracheal tubes must be undertaken with extreme care and, where possible, by an experienced person.

\section{Acknowledgments}

We would like to thank Dr R. T. S. Gunn for permission to 
describe his patient, and Professor F. Cockburn for his helpful advice. We also thank Miss Fiona Paton for typing the manuscript.

\section{References}

BricheteaU, M. (1844) Observation d'hydro-pneumopéricarde, accompagné d'un bruit de fluctuation perceptible à l'oreille. Archives Générales de Médecine, 4, 334.

CurRy, N. \& ANDerson, R.S. (1974) Pneumopericardium and esophago-pericardial fistula following chronic esophagitis presenting as acute respiratory distress. Chest, 66, 731 .

Fearon, B., MacDonald, R.E., Smith, C. \& Mitchell, D. (1966) Airway problems in children following prolonged endotracheal intubation. Annals of Otology, Rhinology and Laryngology, 75, 975.

FreEMAN, G.R. (1972) A comparative analysis of endotracheal intubation in neonates, children and adults: complications, prevention and treatment. Laryngoscope, $82,1385$.

Johannides, M. \& Tsoulos, G.D. (1930) The etiology of interstitial and mediastinal emphysema. Archives of Surgery, 21, 333.

KHAN, R.M.A. (1974) Air tamponade and tension pneumopericardium. An unusual complication of subtotal pericardiectomy. journal of Thoracic and Cardiovascular Surgery, 68, 328.

LIEUTAUD, J. (1767) Historia anatomica-medica sistens numerosissima cadaverum humanorum extispicia. Tomus Secundus, p. 71. Vincent, Paris.

LofTis, J.W., Susen, A.F., Marcy, J.H. \& Sherman, F.E. (1962) Pneumopericardium in Infancy. American Journal of Diseases of Children, 103, 61.
McGovern, F.H., Fitz-Hugh, G.S. \& Edgemon, J.L. (1971) The hazards of endotracheal intubation. Annals of Otology, Rhinology and Laryngology, 80, 556.

Mansfield, P.B., Graham, C.B., Beckwith, J.B., Hall, D.G. \& Sauvage, L.R. (1973) Pneumopericardium and pneumomediastinum in infants and children. Journal of Pediatric Surgery, 8, 691.

Matthieu, J., Nussle, D., Torrado, A. \& Sadeghi, H. (1970). Pneumopericardium in the newborn. Pediatrics, 46, 117.

Monro, J.L., Nicholls, R.J., Hately, W., Murray, R.S. \& Flavell, G. (1974) Gastropericardial fistula-a complication of hiatus hernia. British Journal of Surgery, 61, 445.

Moodie, D.S., Kleinberg, F., Hattery, R.R. \& Feldt, R.H. (1976) Neonatal pneumopericardium. Proceedings. Mayo Clinic, 51, 101.

Netro, D.J.L. (1944) Pneumopericardium in a forty-two day old infant. American Journal of Diseases of Children, 67, 288.

Sandler, C.M., Libshitz, H.I. \& Marks, G. (1975) Pneumoperitoneum, pneumomediastinum and pneumopericardium following dental extraction. Radiology, 115, 539.

SCOTT, J.K. \& Viner, J. (1975) Surgical emphysema, bilatera, pneumothorax, pneumomediastinum and pneumoperitoneum complicating intubation for anaesthesia. Postgraduate Medical Journal, 51, 654.

SHACKELFORD, R.T. (1931) Hydropneumopericardium. Journal of the American Medical Association, 96, 187.

Thompson, D.S. \& ReAD, R.C. (1968) Rupture of the trachea following endotracheal intubation. Journal of the American Medical Association, 204, 995. 